\title{
As notificações de acidentes de trabalho com material biológico em um hospital de ensino de Curitiba/PR
}

\author{
Reporting on work accidents with biological materials in a teaching hospital in the city of \\ Curitiba, state of Paraná, Brazil \\ Rafaela Gessner¹, Liliana Müller Larocca², Maria Marta Nolasco Chaves³, Suzana Dal-Ri Moreira, \\ Elizabeth dos Santos Wistuba5, Silvia Jaqueline Pereira de Souza ${ }^{6}$
}

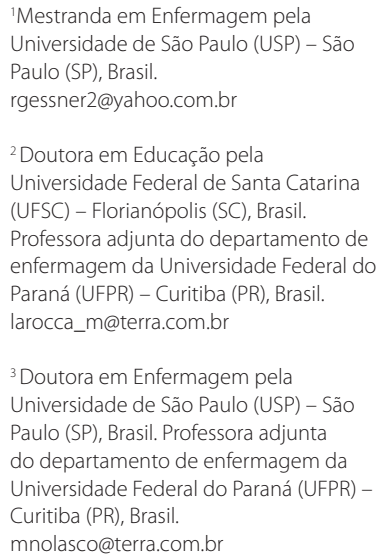

${ }^{4}$ Residência médica em Clínica Médica no Hospital Heliópolis - Sacomã (SP), Brasil. Chefe do Serviço de Epidemiologia do Hospital de Clínicas da UFPR - Curitiba (PR), Brasil.

sumoreira@brturbo.com.br

${ }^{5}$ Especialista em Pneumologia Sanitaria pela Escola Nacional de Saúde Pública Sério Arouca da Fundação Oswaldo Cruz (ENSP/FIOCRUZ) - Rio de Janeiro (RJ),

Brasil. Especialista em Saude Coletiva

pela Universidade Positivo (UP) - Curitiba (PR), Brasil.

eswistuba@hotmail.com

${ }^{6}$ Mestranda em Enfermagem Universidade Federal do Paraná (UFPR) Curitiba (PR), Brasil.

silviajaquel@gmail.com
RESUMO: Estudo descritivo, de natureza qualitativa, com o objetivo de conhecer a realidade da notificação de acidentes de trabalho com material biológico no Serviço de Epidemiologia Hospitalar de Hospital de Ensino de Curitiba - PR. A coleta de dados foi realizada em bancos de dados do SINAN-Net e por meio de entrevistas semiestruturadas com dez informantes- chave. A análise dos dados, fundamentada no materialismo histórico e dialético, permitiu identificar processos relacionados às dimensões estrutural, particular e singular na notificação dos acidentes de trabalho.

PALAVRAS-CHAVE: Saúde coletiva; Enfermagem; Saúde do trabalhador.

ABSTRACT: This is a descriptive study based on qualitative methods aimed at outlining the connection between occurrence and lack of reporting of occupational accident with biological material reported in a teaching hospital at Curitiba, Parana State, Brazil. Data collection involved searching report made in 2010 by the Epidemiology unit and semi-structured interviews with key informants from a hospital. Data were examined according to historical and dialectical materialism that led to the identification of structural, specific and unique aspects of occupational accident reports.

KEYWORDS: Collective health; Nursing; Occupational health. 


\section{Introdução}

Os acidentes de trabalho caracterizam-se como um problema de saúde pública, com efeitos deletérios à saúde do trabalhador. No Brasil, de acordo com o Anuário Estatístico da Previdência Social de 2009, foram registrados 723.452 acidentes de trabalho, dentre os quais 57.606 referentes a trabalhadores dos serviços de saúde e serviços sociais (BRASIL, 2009a).

O Sistema de Informação de Agravos de Notificação (SINAN) foi desenvolvido em 1993 com o objetivo de coletar e processar dados sobre agravos de notificação em todo o País. Alimenta-se pela notificação e investigação de casos de doenças e agravos que constam na lista nacional de doenças de notificação compulsória, entre eles o agravo acidente de trabalho com exposição a materiais biológicos, conforme Portaria GM/MS n 104, de 25 de janeiro de 2011.

Os profissionais da área da saúde, sobretudo os da Enfermagem, são constantemente expostos a riscos de acidentes de trabalho. Uma das características do processo de trabalho da Enfermagem, especialmente em ambientes hospitalares, é a proximidade física com os usuários e a realização de procedimentos invasivos. Portanto, é comum o contato, mesmo que indireto, com fluidos orgânicos (SOARES, et al., 2011). Nesse processo, os trabalhadores ficam susceptíveis a infecçóes por agentes patogênicos veiculados pelo sangue, tais como o vírus HIV e os vírus HVB e HCV (BRASIL, 2009b).

Ademais, a alta carga de trabalho desempenhada pelos trabalhadores da Enfermagem causa desgastes e prejudica os relacionamentos interpessoais. É frequente a dilatação da jornada de trabalho, seja por mais de um vínculo empregatício ou pela adição de horas extras. Assim, o trabalhador tem sofrido com a falta de concentração e fortes pressóes psicoemocionais. Destaca-se que a composição da força de trabalho da equipe de Enfermagem é majoritariamente feminina e é comum às mulheres a dupla jornada de trabalho, dado que o trabalho doméstico ainda é visto como responsabilidade feminina mesmo quando formalmente inseridas no mercado de trabalho (ZIBETTI; PEREIRA, 2010).

A divisão social do trabalho, a formação técnica em níveis de escolaridade diferentes e o quantitativo de trabalhadores imprimem ao enfermeiro as atividades intelectuais e aos auxiliares e técnicos de Enfermagem as atividades ditas manuais. Destarte, aos executores da intervenção se impóes maior risco de acidentes de trabalho. Somam-se, ainda, a esses processos, o trabalho executado em diferentes turnos e a constante vivência de tensóes e estresses no trabalho, como a morte e o sofrimento de usuários e familiares (RIBEIRO; SHIMIZU, 2007).

\section{Acidente de trabalho e o materialismo histórico dialético}

Conforme Egry (1996), a saúde, enquanto estrutura e sistema, determina-se pela relação entre os modos de produção e a inclusão dos indivíduos nesse sistema. É nessa relação que o indivíduo será exposto a processos protetores da sua saúde, bem como de desgastes e contradiçóes que determinarão a sua relação saúde-doença.

Dessa forma, ao se analisar o fenômeno acidente de trabalho, é necessário refletir sobre a realidade objetiva estudada e seu desdobramento em três dimensōes: estrutural, formada pelo desenvolvimento da capacidade produtiva e das relaçóes de produção econômicas e político-ideológicas; particular, constituída pelos processos de reprodução social e perfis epidemiológicos de classe, ou seja, pelas formas únicas de produção e consumo em cada classe; e singular, formada pelos processos que, em última instância, levam o sujeito a adoecer e morrer ou a desenvolver o aperfeiçoamento de sua saúde (EGRY, 1996).

Autores como Sarquis e Felli (2009) referendam a determinação estrutural para os acidentes de trabalho, destacando a escassez de recursos humanos na maioria das instituições, o que impóe o aumento do ritmo e da carga de trabalho nesses locais.

A razão significativa para a escolha deste tema foi a percepção de que os dados referentes às notificaçóes de acidentes de trabalho poderiam ser o reflexo da subnotificação desse agravo na instituição. Parte significativa das notificações (32\%) diz respeito a acidentes envolvendo materiais biológicos de pacientes-fonte sabidamente positivos para algumas infecçóes - HIV, HCV 
e HBV -, o que não está de acordo com a realidade da incidência da infecção no País $(0,61 \%)$ e com o risco de infecção pelo vírus HIV após acidentes percutâneos $(0,3 \%)$. Neste estudo, partiu-se do pressuposto que a maior parte dos trabalhadores notifica os seus acidentes, principalmente quando conhece a situação sorológica positiva do paciente-fonte.

Assim, tem por objetivo conhecer a realidade das notificaçóes de acidentes de trabalho com material biológico no Serviço de Epidemiologia Hospitalar de Hospital de Ensino localizado no município de Curitiba$-\mathrm{PR}$, relacionando sua ocorrência e subnotificação.

\section{Materiais e métodos}

Trata-se de estudo de natureza qualitativa, classificado quanto aos fins como descritivo e quanto aos meios como estudo de caso, visto que se aplica a uma unidade de análise (TOBAR; YALOUR, 2001).

Realizou-se a coleta dos dados em duas etapas. $\mathrm{Na}$ primeira, levantaram-se as notificaçóes de acidentes de trabalho com exposição a material biológico notificados no Serviço de Epidemiologia Hospitalar (SEPIH) de Hospital de Ensino da cidade de Curitiba-PR no ano de 2010. Na segunda etapa, realizaram-se entrevistas semiestruturadas com informantes-chave acerca das condiçóes em que aconteceram os acidentes de trabalho notificados.

Como critério de inclusão da primeira etapa, selecionaram-se notificaçóes de acidentes de trabalho com exposição a material biológico realizadas no SEPIH entre janeiro e dezembro de 2010. Como critério de inclusão de participantes para a segunda etapa da pesquisa, selecionaram-se informantes-chave cujo processo de trabalho incluísse atividades de gerência nas unidades que apresentavam maior frequência de acidentes notificados. Dessa forma, o universo da pesquisa foi constituído, na primeira etapa, por 63 acidentes de trabalho com exposição a materiais biológicos notificados e constantes do banco de dados, cujo acesso realizou-se entre 1 de agosto e 30 de agosto de 2011. Na segunda etapa, a amostra foi constituída pelas entrevistas realizadas com dez enfermeiros de oito unidades diferentes no período de 22 de agosto a 11 de setembro de 2011.

A análise qualitativa dos dados foi inspirada nas Bases Metodológicas para a Assistência de Enfermagem em Saúde Coletiva fundamentadas no Materialismo Histórico e Dialético apresentadas por Egry (1996), com destaque para a etapa de captação da realidade objetiva e identificação das dimensóes estrutural, particular e singular.

O estudo integra o projeto "Promoção da saúde e prevenção de agravos no âmbito da epidemiologia hospitalar na perspectiva da saúde coletiva”, aprovado pela Universidade Federal do Paraná sob o protocolo CAAE 0076.0.091.000-10. Todos os trâmites legais e éticos requeridos pela Resolução n $n^{\circ}$ 466/12 do Conselho Nacional de Saúde foram seguidos.

\section{Resultados e discussão}

A primeira etapa da pesquisa quantificou os casos de acidente de trabalho com exposição a material biológico notificados no SEPIH em 2010. No período estudado, foram notificados 63 acidentes de trabalho com exposição a materiais biológicos, dos quais 49 (78\%) acometeram mulheres, a maior parte da força de trabalho da instituição, e 14 (22\%) ocorreram com homens. Tais dados vêm ao encontro da realidade estadual de notificação do agravo, pois, no estado do Paraná, entre 2006 e 2010, foram notificados mais de 10 mil acidentes de trabalho com material biológico, dos quais aproximadamente oito mil ocorreram com mulheres (PARANÁ, 2011).

Ruiz, Barboza e Soler (2004) e Balsamo e Feli (2006) mostram em seus estudos que a maior incidência de acidentes de trabalho com material biológico está na categoria de Auxiliares de Enfermagem, realidade que se repete no cenário estudado, onde a incidência de acidentes nessa categoria representou 32\% (20 acidentes).

O grupo estudantes representou a segunda colocação em número de acidentes, totalizando doze ocorrências (19\%): dez alunos acidentados pertenciam ao curso de medicina; um aluno, ao curso de Enfermagem; e outro de curso não especificado. Tais dados se assemelham 
a uma pesquisa de 2004 , na qual $40 \%$ dos acidentes, em hospital de ensino de São Paulo, aconteceram com estudantes (GIR; CANINI, 2004). Tornam-se necessárias, portanto, medidas de investimento na educação superior dos profissionais da saúde, a fim de formar profissionais com habilidades e competências para minimizar riscos e adotar medidas de segurança.

Quanto ao tipo de exposição, corroborando Caixeta e Branco (2005), a maior frequência foi de acidentes percutâneos, com 47 casos (75\%), seguidos de exposição mucosa, onze casos (17\%), e pele íntegra ou não íntegra, cinco casos (8\%). Em 50 casos (80\%), o material envolvido nas lesôes foi o sangue; materiais não identificados foram notificados em dez casos (15\%); e o líquido pleural, em três (5\%). Em relação ao uso de EPI, verifica-se que 57 (90\%) dos acidentados usavam luvas e avental no momento do acidente, e apenas oito (13\%) usavam óculos de proteção. Ruiz, Barboza e Soler (2004) defendem que o uso de EPIs constitui medida preventiva capaz de produzir impacto no número de acidentes de trabalho. Entretanto, sabese que condiçóes de trabalho adversas, a que muitos trabalhadores estão expostos, devem ser consideradas como propiciadoras na ocorrência desses acidentes, e náo somente o uso inadequado ou a falta de uso do equipamento de segurança.

Em 56 casos (88\%), a fonte era conhecida em relação ao paciente-fonte, sendo 38 (68\%) negativos e 18 (32\%) positivos. Destes últimos, onze $(19,5 \%)$ eram Anti-HIV, seis (11\%) Anti-HCV, cinco (9\%) Anti-HBs e quatro (7\%) Anti-HbsAg. A contagem ultrapassa os 18 positivos porque há pacientes-fonte com infecção HIV e Hepatite C.

A quantidade de pacientes-fonte positivos (32\%) é alta e permite inferir que não está de acordo com a realidade da incidência da infecção no País $(0,61 \%)$ e com o risco de infecção pelo vírus HIV após acidentes percutâneos $(0,3 \%)$. Esses números indicam a possibilidade de subnotificação dos acidentes de trabalho, partindo-se do pressuposto que a maior parte dos trabalhadores notifica os seus acidentes, principalmente quando conhecem a situação sorológica positiva do paciente-fonte, dificultando, dessa maneira, apesar dos grandes avanços recentes, o completo conhecimento da realidade desse agravo no local da pesquisa, bem como em outras instituições de saúde.

\section{Interpretação da realidade objetiva}

Para compreensão da relação entre acidentes de trabalho com exposição a material biológico e sua subnotificação, ancorou-se na Teoria da Intervenção Práxica de Enfermagem em Saúde Coletiva (TIPESC) proposta Egry (1996) e fundamentada no materialismo histórico dialético. Na TIPESC, considera-se que o processo saúde doença (GRANDA; BREIHL, 1989) é socialmente determinado, pois advém das transformaçōes sociais ocorridas em um determinado momento histórico, gerando transformaçóes na saúde, tanto na sua estrutura como no sistema de saúde. Esse referencial pressupóe, para a sua compreensão, um reconhecimento da realidade objetiva, em suas três dimensóes: estrutural, particular e singular, aqui consideradas como categorias analíticas. Portanto, a interpretação da realidade objetiva no que tange à subnotificação em relação aos acidentes de trabalho com exposição a materiais biológicos foi realizada por meio da identificação, após transcrição das falas dos informantes-chave, de elementos pertencentes às três dimensôes acima citadas.

\section{Dimensão estrutural}

Neste estudo, compreende-se a dimensão estrutural nos aspectos jurídico-legais da Saúde no Brasil, bem como naqueles relativos ao acesso educacional, seja na formação geral ou na educação permanente dos trabalhadores. Considera-se, também, como parte estrutural, o trabalho sob a perspectiva ontológica do termo.

A Constituição Federal (CF) Brasileira, em seu artigo sexto, afirma que são direitos sociais: a educação, a saúde, a alimentação, o trabalho, a moradia, o lazer, a segurança, a previdência social, a proteçáo à maternidade e à infância e a assistência aos desamparados. O artigo 196 dispóe que a saúde é direito de todos e dever do Estado, garantido mediante políticas sociais e econômicas que visem à redução do risco de doença e 
de outros agravos e ao acesso universal e igualitário às açôes e serviços para sua promoção, proteção e recuperação (BRASIL, 1988).

Entretanto nota-se que esse direito não está presente quando se trata de aspectos da saúde do trabalhador. Quando se questionou um informante-chave a respeito de quais fatores poderiam contribuir para a comunicação do acidente de trabalho, a seguinte resposta chamou a atenção:

\section{[...] o relacionamento da equipe, a cobrança, você estar sempre orientando e tentando man- ter não uma educação permanente, um trei- namento constante, é difícil porque o número de pessoal é muito reduzido, você não consegue tirar hoje um funcionário nem 15 minutos pra você fazer um treinamento básico sobre nada, quanto mais pra um assunto detalhado e im- portante como esse. (Enf. 4)}

Analisando essa fala, observa-se que as atuais condiçôes do processo de trabalho, caracterizadas pela falta de funcionários e sobrecarga de funções, impedem ou dificultam investimentos na saúde do trabalhador, como a educação permanente. $\mathrm{O}$ impedimento para se afastar o trabalhador do setor para, por exemplo, realização de treinamentos e capacitações implica sua exposição sem que haja orientação para a proteção à saúde.

O processo de trabalho em saúde é determinado por relaçôes sociais, nas quais há uma hierarquização de poderes entre categorias profissionais distintas. Conforme Oliveira e Murofuse (2001) apud Siqueira et al. (1995), as alteraçóes tecnológicas ocorridas, de um lado, implicam um processo mais coletivo, na medida em que as tarefas de um grupo profissional dependem de outro, mas, por outro lado, levam a uma concentração das atividades reflexivas e de maior autonomia em apenas alguns grupos profissionais, relegando uma proporção cada vez maior de trabalhadores a atividades rotineiras e padronizadas.

Chegou-se à conclusão que elementos presentes na dimensão estrutural da sociedade e suas contradiçôes são capazes de explicar, em parte, fatores que acarretam a subnotificação dos acidentes de trabalho com exposição a materiais biológicos. Para alcançar a notificação fidedigna desse agravo, fazem-se necessários o cumprimento das legislaçóes vigentes e o estabelecimento de relaçóes éticas no mundo do trabalho.

\section{Dimensão particular}

Como referencial de análise para a dimensão particular, destaca-se o trabalho em saúde: sua organização, jornada, relações de poder, acidentes de trabalho e sua subnotificação.

Quando se questionou sobre quais fatores poderiam contribuir para a ocorrência de um acidente de trabalho com exposição a materiais biológicos, os dez entrevistados citaram diversas questóes que remetiam à dimensão particular: quatro citaram o desconhecimento sobre a necessidade do uso de EPIs; dois informaram a falta de EPIs na unidade em que atuam; dois informaram o horário de trabalho noturno; quatro, a situação sorológica positiva conhecida do paciente; quatro, a situação sorológica desconhecida; seis citaram o descarte de Resíduos de Serviços de Saúde (RSS) de maneira inadequada; cinco elencaram a falta de materiais para realizar procedimentos e oito mencionaram a falta de treinamentos ou capacitaçóes que tratem da problemática dos acidentes de trabalho na unidade em que atuam. Muitos dos itens elencados dizem respeito às condiçóes do processo de trabalho em saúde no local pesquisado, as quais, de maneira geral, se repetem na maioria das instituiçóes de saúde brasileiras.

Conforme Elias e Navarro (2006), o excesso de trabalho, as jornadas elevadas e um alto número de usuários do sistema de saúde, aliados à tensão, ao estresse, ao cansaço e à fadiga, podem gerar desatenção e descuido no desenvolvimento da prática profissional, influenciando, portanto, na ocorrência de possíveis acidentes, na medida em que os sentimentos e as emoçóes dos trabalhadores de Enfermagem interferem no seu modo de agir e pensar.

A precarização do trabalho, fenômeno que vem se intensificando nos últimos anos em decorrência do acirramento do capitalismo iniciado na década de 1970, é responsável pela pior condição de saúde dos 
trabalhadores e pelo aumento das doenças relacionadas ao trabalho. Destacam-se os aspectos trabalhistas como a baixa remuneraçáo, exclusão do mercado formal de trabalho, desemprego, altas cobranças psicológicas no ambiente de trabalho e pouca autonomia (BRAGA; CARVALHO; BINDER, 2010).

\section{[...] mas, infelizmente, a gente é engolido pelo} tempo, e a gente acaba náo fazendo todo dia essa orientação, a gente acaba orientando quando acontece [...](Enf. 7)

Depreende-se do trecho acima que o processo de trabalho existente no local pesquisado evidencia sua precarização: trabalho exaustivo como impedimento de capacitaçóes e treinamentos. Considera-se a questão da subnotificação como um dos critérios da dimensão particular, neste estudo caracterizada pelo trabalho em saúde. $\mathrm{O}$ trecho a seguir permite inferir que o informante identifica, como responsável pela subnotificação do agravo, a falta de interesse do acidentado ou o fato de o acidentado encarar a lesáo como algo rotineiro e inofensivo: "[...] A negligência [...] o descaso que acontece [...]” (Enf. 4)

Na perspectiva dialética de evidenciar as contradiçôes, é necessário compreender as relaçóes de trabalho (DEJOURS, 1992) existentes no ato da notificação de um acidente de trabalho com material biológico e suas possíveis consequências, como: a exposição do trabalhador, o medo advindo desse processo, as consequências do uso da quimioprofilaxia e o impacto desse evento em sua vida pessoal.

Remetendo-se à relação subnotificação e demora no atendimento: "[...] é estressante [...] você tem que esperar o atendimento [...] depois se o paciente for soropositivo você tem que tomar aquele coquetel [...] é tanta burocracia."(Enf. 8)

A demora no atendimento ambulatorial é entendida por parte dos entrevistados como determinante na notificação do agravo. Tal afirmação levanta uma contradição: os serviços de saúde são cada vez mais exigidos para oferecer atendimento rápido e de qualidade aos usuários, mas essa não é a realidade quando os funcionários tornam-se usuários.
A falta de informação também foi identificada como causa para a subnotificação: "[...] por falta de informação, por falta de achar importante, desconhecimento." (Enf. 10)

É importante ressaltar que mudanças paradigmáticas no processo de trabalho em saúde são imprescindíveis à compreensão dos acidentes de trabalho. Medidas de educação continuada a respeito do tema acidente de trabalho contribuem para o esclarecimento sobre a necessidade da notificação, acompanhamento e tratamento desse agravo.

Destacou-se, ainda, como causa para a subnotificação, o conhecimento prévio da situação sorológica positiva do paciente-fonte por parte do trabalhador, determinando, assim, maior preocupação na ocorrência da lesão. Pode-se inferir que esse comportamento se reflete, também, na maior notificação do acidente sofrido, explicando, em parte, porque uma grande parcela (32\%) das notificaçóes de acidentes de trabalho com material biológico no cenário pesquisado diz respeito a pacientesfonte positivos:

\section{[...] quando você sabe que um paciente é so- rologicamente positivo, independente de qual agente causador dessa sorologia positiva, você tem cuidado, e gera em você uma preocupação.} (Enf. 4)

É possível reconhecer que as condiçóes adversas e precárias presentes na dimensão particular - intensificação do processo de trabalho, pouca autonomia, estresse, entre outros fatores - influenciam na ocorrência de acidentes de trabalho bem como na postura do trabalhador frente a esses eventos.

\section{Dimensão Singular}

Nessa dimensão, aborda-se como a dinâmica individual de manutenção de vida interfere na notificação ou subnotificação do agravo investigado, podendo-se destacar questóes subjetivas relacionadas ao medo. Nessa etapa, estabeleceu-se relação com as representaçôes individuais sobre o processo saúde doença: "[...] tem funcionário 
que acha que náo precisa tomar o coquetel, porque o paciente não tem ou a gente não tem o conhecimento que é soropositivo [...]" (Enf. 6)

Em algumas situaçóes, a interpretação do processo saúde-doença pode ser considerada individual e subjetiva, influenciada pela inter-relação entre os seres humanos e os elementos que os cercam, bem como pelos sentimentos de culpa, medo, superstiçôes e mistérios. Essas questốes estão intimamente ligadas às expressóes de cada doença, à ocorrência de epidemias, ao sofrimento e à dor, ao desgaste físico e mental e à expectativa da morte (SEVALHO, 1993).

\section{[...] eles ficam com muito medo [...] teve um funcionário que estava fazendo uma gasome- tria [...] e se picou com a agulha e teve que recolher todos os exames e ele ficou super preo- cupado, super ansioso até sair o resultado [...] porque ele estava se achando doente sabe? [...] (Enf. 5)}

Analisando essa fala, percebe-se que a maneira de vivenciar o acidente de trabalho é subjetiva. Para muitos profissionais de saúde, a indicação do tratamento profilático dimensiona a gravidade do acidente, pois eles associam esse fato diretamente à contaminação pelo vírus HIV. Vários fatores influenciam a possibilidade de aceitar e reconhecer o tratamento como necessário: o significado e representação que o trabalhador tem desse acidente em sua vida; o surgimento de efeitos colaterais; o conhecimento prévio da profilaxia, do objetivo das medicaçóes; do sentimento de estar doente; e do medo da discriminação social (BRANDÃO JR., 2000).

Um dos principais sentimentos vivenciados pelos profissionais de Enfermagem no momento pós-acidente de trabalho é o medo (SARQUIS; FELLI, 2009). Na interface estabelecida entre a dimensão particular e a singular, destaca-se que o medo de perder o emprego e do enfrentamento junto aos gestores superou o medo de adoecer. Possivelmente, essa problemática acaba por interferir na notificação, explicitando vulnerabilidades individuais e coletivas.

Contudo, Dejours (1992) salienta que o medo está presente em todas as ocupaçóes profissionais, embora algumas profissóes apresentem mais riscos à integridade física, como a Enfermagem. Contra o medo gerado por sua ocupação, os trabalhadores desenvolvem defesas específicas que podem ser protetoras ou, de forma oposta, desgastantes. Pode-se inferir que o medo é capaz de gerar atitudes protetoras como, por exemplo, o correto uso de EPIs, a notificação de um acidente de trabalho e o uso de medicamentos profiláticos. Por outro lado, se sublimado pelo sistema defensivo do trabalhador, pode gerar uma atitude de negligência em relação à própria saúde:

\section{[...] os mais antigos de profissáo acham assim "ah isso não vai acontecer comigo, se não acon- teceu até agora um acidente", ou, "não pego nada" [...] esses que correm o maior risco são os que menos tomam cuidado. (Enf. 7)}

Pode-se perceber que, na análise da dimensão singular dos trechos destacados, evidenciaram-se, de forma dialética, a dinâmica e a historicidade da sobrevivência, bem como o aperfeiçoamento da saúde com relação ao processo saúde-doença e à sua interpretaçáo. Tal evidência pode ser compreendida pelas formas individuais de participação na organização do trabalho e pelas questóes próprias de interferência em outros níveis, no caso, relaçóes de trabalho, lazer, prazer, qualidade de vida e manifestações do corpo biopisíquico, como o desgaste físico e emocional e a produção de sensaçôes.

\section{Conclusões}

Os acidentes de trabalho com exposição a materiais biológicos constituem um dos graves problemas a que está sujeito o trabalhador da saúde, especialmente aquele que desenvolve suas atividades laborais em instituiçôes hospitalares. Durante a identificação das notificações de acidentes de trabalho com exposição a materiais biológicos realizadas no cenário do estudo constatou-se que há uma subnotificação no que diz respeito a esse evento, informação que foi igualmente percebida após a análise das entrevistas realizadas com os informanteschave, trabalhadores do mesmo hospital. 
O fenômeno da precarização do trabalho, explicitado por características como a má remuneraçáo, pouca autonomia, necessidade de dupla jornada e excesso de demandas, exerce influência no ato da notificação dos acidentes sofridos, impedindo, por diversas vezes, a notificação fidedigna desse agravo e reforçando o pensamento de que só se deve "perder" tempo para notificar o acidente quando envolver material biológico de um paciente-fonte positivo.

Muitas vezes, culpa-se o trabalhador pela ocorrência do acidente de trabalho: náo utilização de EPIs, descuido ou desatenção. Porém, deve-se refletir acerca da realidade à qual esse trabalhador está inserido, determinante de processos de proteção e desgaste, fazendo emergir o seguinte questionamento: como os profissionais de saúde vêm sendo preparados para enfrentar um fenômeno de tamanho impacto?

Acredita-se que, mesmo contemplando um cenário específico, as dimensóes aqui reconhecidas, com destaque para a dimensão estrutural, são passíveis de generalização para outras instituiçóes de trabalho em saúde.

Faz-se necessário salientar a importância da correta e efetiva notificação dos acidentes de trabalho, pois a notificação gera o panorama da ocorrência desse agravo em diferentes regióes, subsidiando a produção de políticas públicas. Como salientam Miquilin e Filho (2011), a construção de um contexto de saúde do trabalhador que reflita os ideais de justiça, cidadania e universalidade deve, necessariamente, considerar os trabalhadores, a instituição e o Estado.

\section{Referências}

BRAGA, L.C.; CARVALHO, L.R.; BINDER, M.C.P. Condições de trabaIho e transtornos mentais mais comuns em trabalhadores da rede básica de saúde de Botucatu (SP). Ciência e Saúde Coletiva, v.15, n.1, p.1585-1596, 2010

BRANDÃO JUNIOR, P. S.. As dimensões psicossociais do acidente com material biológico no trabalho em hospital. Dissertação (Mestrado em Ciências na Área da Saúde Pública) - Escola Nacional de Saúde Pública, Ministério da Saúde, Fundação Oswaldo Cruz, Rio de Janeiro, 2000.

BRASIL. Constituição: República Federativa do Brasil (1988). Brasília, DF: Senado Federal, 1988.

Ministério da Previdência social. Anuário Estatístico da Previdência Social 2009. Brasília 2009a. Disponível em: < http://www. mpas.gov.br/conteudoDinamico.php?id=989>. Acesso em: 21 abril 2011.

Ministério da Saúde. Secretaria de Vigilância em Saúde. Departamento de Vigilância Epidemiológica. Guia de vigilância epidemiológica. 7. ed. Brasília: Ministério da Saúde, 2009b.

CAIXETA, R.B.; BRANCO, A.B. Acidentes de trabalho, com material biológico, em profissionais de saúde de hospitais públicos do Distrito Federal, Brasil, 2002/2003. Cadernos de Saúde Pública, v.21, n.3, p.737-746, 2005.
DEJOURS, C. A loucura do trabalho: estudo de psicopatologia do trabalho. 5. ed. ampliada. São Paulo: Cortez Editora, 1992.

EGRY, E.Y. Saúde coletiva: construindo um novo método em Enfermagem. São Paulo: Ícone, 1996.

ELIAS, M.A.; NAVARRO, V.L. A relação entre o trabalho, a saúde e as condições de vida: negatividade e positividade no trabalho das profissionais de enfermagem de um hospital escola. Revista Latino-Americana de Enfermagem, v.14, n.4, p.517-525, 2006.

GIR, R.K.R.E.; CANINI, S.R.M.S. Accidents with biological material among undergraduate nursing students in a public Brazilian University. The Brazilian Journal of Infectious Diseases, v.8, n.1, p.18-24, 2004.

GRANDA, E.; BREILH, J. Saúde na Sociedade: guia pedagógico sobre um novo enfoque do método epidemiológico. 2. ed. São Paulo: Cortez Editora, 1989.

MIQUILIN, I.O.C.; FILHO, H.R.C. Propostas de inclusão dos trabalhadores informais e desempregados nas políticas públicas brasileiras: breve análise a partir das Conferências Nacionais de Saúde do Trabalhador. Saúde em Debate, v.35, n.90, p.426-436, 2011.

OLIVEIRA, B.R.G.; MUROFUSE, N.T. Acidentes de trabalho e doença ocupacional: estudo sobre o conhecimento do trabalhador hospitalar dos riscos à saúde de seu trabalho. Revista Latino-Americana de Enfermagem, v.9, n.1, p.109-115, 2001. 
PARANÁ. Secretaria do Estado da Saúde. Centro Estadual de Saúde do Trabalhador. Relatório SINAN, 2011 (dados preliminares).

RIBEIRO, E.J.G.; SHIMIZU, H.E. Acidentes de trabalho com trabalhadores de Enfermagem. Revista Brasileira de Enfermagem, v.60, n.5, p.535-540, 2007.

RUIZ, M.T.; BARBOZA, D.B.; SOLER, Z.A.S.G. Acidentes de trabalho: um estudo sobre esta ocorrência em um hospital geral. Arquivos de Ciências da Saúde, v.11, n.4, p. 219-224, 2004.

SARQUIS, L.M.M.; FELLI, V.E.A. Os sentimentos vivenciados após exposição ocupacional entre trabalhadores de saúde: fulcro para repensar o trabalho em instituições de saúde. Revista Brasileira de Enfermagem, v.62, n.2, p.701-704, 2009.
SOARES, L.G.; et al. Risco biológico em trabalhadores de Enfermagem: promovendo a reflexão e a prevenção. Cogitare Enfermagem, v.16, n.2, p.261-267, 2011.

TOBAR, F.; YALOUR, M.R. Como fazer teses em saúde pública: conseIhos e ideias para formatar projetos e redigir teses e informes de pesquisas. Rio de Janeiro: Editora Fiocruz, 2001.

Recebido para publicação em junho de 2012

Versão final em dezembro de 2013

Conflito de interesse: não hovue

suporte financeiro: inexistente 